\title{
EXHAUST GAS TEMPERATURE MEASUREMENTS IN DIAGNOSTICS OF TURBOCHARGED MARINE INTERNAL COMBUSTION ENGINES PART I
}

\author{
STANDARD MEASUREMENTS
}

\author{
Zbigniew Korczewski, Prof. \\ Gdańsk Univeristy of Technology, Poland
}

\begin{abstract}
The article discusses the problem of diagnostic informativeness of exhaust gas temperature measurements in turbocharged marine internal combustion engines. Theoretical principles of the process of exhaust gas flow in turbocharger inlet channels are analysed in its dynamic and energetic aspects. Diagnostic parameters are defined which enable to formulate general evaluation of technical condition of the engine based on standard online measurements of the exhaust gas temperature. A proposal is made to extend the parametric methods of diagnosing workspaces in turbocharged marine engines by analysing time-histories of enthalpy changes of the exhaust gas flowing to the turbocompressor turbine. Such a time-history can be worked out based on dynamic measurements of the exhaust gas temperature, performed using a specially designed sheathed thermocouple.

The first part of the article discusses possibilities to perform diagnostic inference about technical condition of a marine engine with pulse turbocharging system based on standard measurements of exhaust gas temperature in characteristic control cross-sections of its thermal and flow system. Selected metrological issues of online exhaust gas temperature measurements in those engines are discusses in detail, with special attention being focused on the observed disturbances and thermodynamic interpretation of the recorded measuring signal. Diagnostic informativeness of the exhaust gas temperature measurements performed in steady-state conditions of engine operation is analysed in the context of possible evaluations of technical condition of the engine workspaces, the injection system, and the fuel delivery process.
\end{abstract}

Keywords: diagnostic, internal combustion engine, exhaust gas temperature

\section{INTRODUCTION}

The exhaust gas temperature in the internal combustion engine, measured in characteristic control cross-sections of its thermal and flow system, can be a valuable source of diagnostic information about technical condition of elements limiting particular engine workspaces, including the supercharging system, the fuel supply system, and the working medium exchange system. In standard measuring systems installed on marine engines equipped with pulse turbocharging system the exhaust gas temperature is measured at the outlets of particular cylinders, and at the turbocompressor turbine inlet and outlet. The measurements are performed using traditional thermocouples with relatively high measuring inertia (time constants of the order of tenths of a second and more) [Kluj, 2000]. That means that further diagnostic analyses make use of averaged values of the periodically changing exhaust gas temperature measured at outlets of particular engine cylinders, in the exhaust manifold in front of the turbine, and in the turbine outlet channel - see Fig. 1. The most serious metrological difficulty in this case is correct interpretation of the temperature signal recorded in steady-state conditions of engine operation [Wiśniewski 1983], and the basic problem faced by a diagnostician is to answer the question how much the directly observed thermocouple indications differ from the real temperature of the exhaust gas which can be determined indirectly by measuring other state parameters of the thermodynamic medium. In fact, these differences provide opportunities to explain some peculiarity, or even apparent anomaly, of the exhaust gas system in turbocharged engines, in which the averaged temperature of the exhaust gas leaving particular cylinders is much lower (even by more than $100 \mathrm{~K}$ !) from the averaged temperature of the exhaust gas in the turbocompressor exit cross-section. 
a)

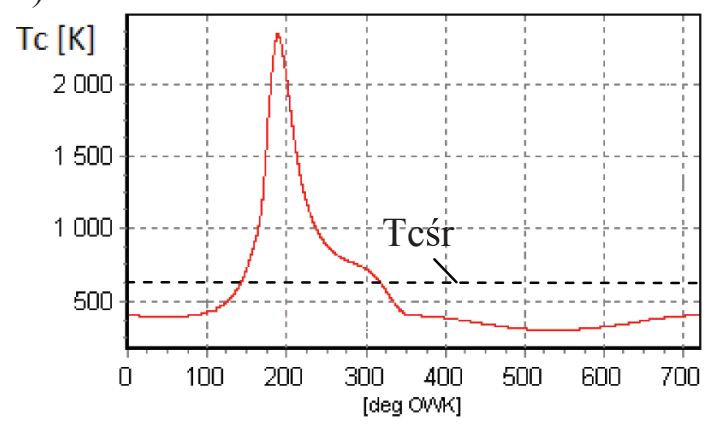

b)

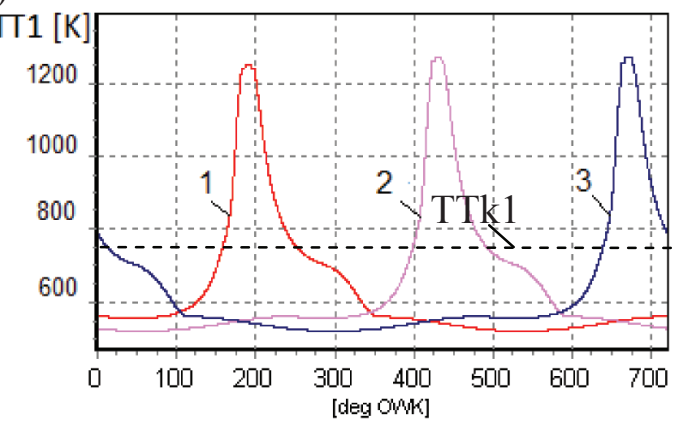

c)

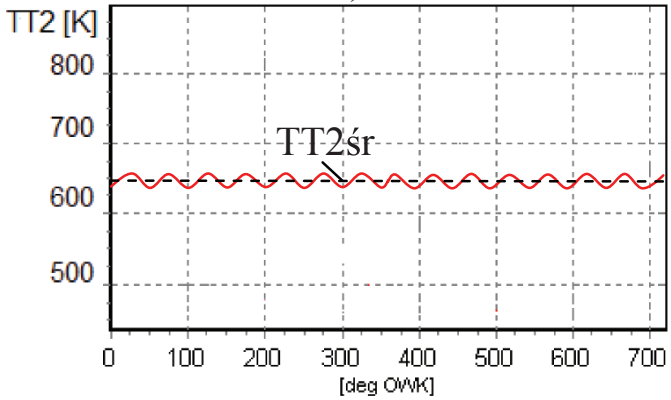

Fig. 1. Exhaust gas temperature fluctuations at cylinder exit (a), in the exhaust manifold in front of the turbine (b) and in turbine outlet channel (c), as function of the crankshaft rotation angle in four-stroke engine

\section{THERMODYNAMICS OF EXHAUST GAS FLOW}

Energy conversion processes executed in the functional systems of the marine engine with pulse turbocharging can be analysed in stationary and non-stationary conditions of operation of the ship motor system ${ }^{1}$ and/or the ship electric power system ${ }^{2}$. When limiting the analysis only to the propulsion engine, we assume that stationary operating conditions have place when the time derivatives of state parameters of the analysed energy conversion processes are equal to zero or reveal periodic nature, with the time period equal to one operating cycle or its multiplication resulting from a certain number of cylinders. In this case the processes of mass and energy accumulation and dispersion in the functional systems of the engine are absent, and the average values of all inlet and outlet energy flows do not change. Consequently, the values of basic engine performance parameters, for instance the generated torque, angular speed of the crankshaft and the rotating system of the turbocompressor, or the total flux of heat flowing through the engine remain unchanged when averaged over the time corresponding to a number of successive operating cycles.

However in a real situation, the time-histories of state process parameters always reveal fluctuations within one cycle of engine operation, which particularly result from unrepeatability of the combustion process [Rychter and Teodorczyk, 2006, Wisłocki, 1991]. This fact can also explain

\footnotetext{
${ }^{1}$ Propulsion engine - propeller - ship hull.

2 Propulsion engine - generator.
}

certain stratification, sometimes relatively high, of indicator diagrams recorded in successive cycles of operation of the same cylinder, for fixed fuel distribution rail on the injection pump and for unchanged rotational speed of the crankshaft. If this stratification leads to changes of the averaged values of engine output parameters which can be observed using the available measuring techniques, we have to conclude that the engine operates in non-stationary conditions due to the appearance of energy and mass accumulators in its functional systems.

In this situation, special care should be taken when analysing simultaneously so-called "micro-dynamic" processes (of high speed of changes) ${ }^{3}$ having place in the engine due to its cyclic operation, and relatively much slower and delayed "macro-dynamic" processes (of low speed of changes) ${ }^{4}$ of mass, heat, and energy flows in the functional systems, taking into account the dynamics of the control processes. Moreover, time constants of "macro-dynamic" processes executed in nonstationary operating states by ship motor systems or power conversion systems, the inertia of which amounts to some or even several dozens of minutes, should be possibly evaluated in relation to "micro-" and "macro-dynamic" engine processes, [Wojnowski, 1998].

When narrowing further the scope of analysis of dynamics of energy conversion processes in marine engines with pulse turbocharging solely to the thermodynamics of the exhaust gas system, two approaches are possible. The first approach assumes that the analysed thermal and flow processes are stationary. In this situation it is assumed that the time-histories

\footnotetext{
3 Time constants of the order of some to some tens of milliseconds.

${ }^{4}$ Time constants of the order of some to some hundreds of seconds.
} 
of these processes are fully periodical and the state functions of the thermodynamic medium in the exhaust manifold between the cylinders and the turbine are calculated based on the values of the state parameters averaged over the time which is much longer than one operating cycle of the engine.

The second approach assumes that the time-histories of functions describing high-speed thermal and flow processes in the exhaust manifold are aperiodic within the duration time of one cycle of engine operation, or aperiodic within the transient time between one stationary state and the other (slow-speed transient processes).

Consequently, a key metrological issue is to predict the nature of changes of the time-histories (measured instantaneous values) of parameters and state functions of the thermodynamic medium in the exhaust manifold in the context of their periodicity: stationary or non-stationary. This prediction decides about the depth and reliability of further diagnosis on the technical condition of the engine, and defines technical requirements concerning the measuring equipment to be used (inertial characteristics of sensors, sampling frequency o the recorded measuring signal, etc.).

\section{OBJECT OF ANALYSIS}

The object of analysis is the thermal and flow system of a six-cylinder four-stroke engine Sulzer, type 6AL20/24, with pulse turbine supply and charge air cooling - Fig. 2.

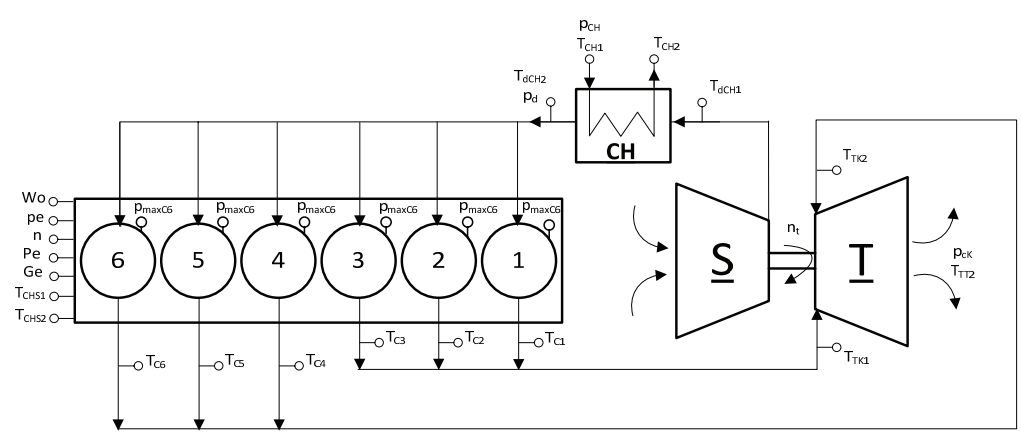

Fig. 2. Scheme of turbo-charging system for Sulzer engine, type 6AL20/24

The nominal power output of the engine is $420 \mathrm{~kW}$, at the rotational speed of the crankshaft is equal to 750 min-1. The remaining technical specifications of the engine are the following: cylinder diameter and capacity - $200 \mathrm{~mm}$ and 7540 $\mathrm{cm} 3$, piston stroke and average speed $-240 \mathrm{~mm}$ and $6,0 \mathrm{~m} / \mathrm{s}$, compression ratio 12,7 . The analysed system comprises the following subsystems: the rotating turbocompressor system with turbine $\mathrm{T}$ and radial compressor $\mathrm{S}$, the air and exhaust gas flow channels, and the engine charge ait cooler $\mathrm{CH}$. The scheme in Fig. 2 also includes points of standard measurements of control parameters of the engine, which are performed on the engine test bed in the shipyard during the acceptance tests. Relevant values of the observed parameters, recorded during stationary operation of a serial engine in five different load ranges, are collected in Table 1 .

A single supercharging system for the engine with fuel injection sequence 1-4-2-6-3-5 is equipped with a radial turbine with two-channel pulse exhaust gas supply. The time-history of exhaust gas pressure changes in channels in front of the turbine is close in nature to that shown in Fig. 3. A solution in which the exit valve is opened during 340 degrees of crankshaft rotation provides a favourable effect of overlapping of the exhaust gas flow pulses (pressure waves) from two cylinders during 100 degrees of OWK. As a consequence, the lowest pressure of the exhaust gas in the exhaust manifold is higher than the outlet backpressure. This leads to the improvement of turbine efficiency, which is, however, obtained on the cost of more work needed to remove the exhaust gas from the engine (higher backpressure in the discharge manifold $)^{5}$

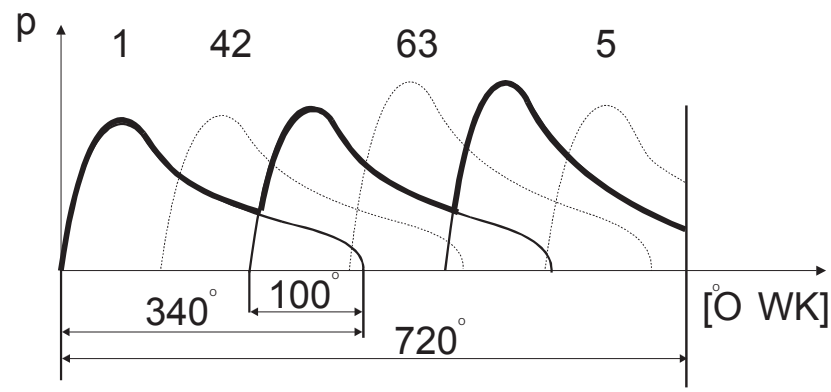

Fig. 3. Exhaust gas pressure changes in the exhaust manifolds K1 (cylinders 1-2-3) and K2 (cylinders 4-5-6) in front of the turbine of Sulzer engine, type $6 A L 20 / 24$

That is why the exhaust manifold is divided into separate branches to which cylinders are connected, taking into account their ignition sequence, in such a way that the exhaust gas pulses from one group of cylinders do not disturb the scavenging process of the other group. Consequently, the exhaust gas outlets of only those cylinders can be connected to a common branch for which the spontaneous ignition distance (measured in OWK degrees) is the same as, or larger than the exhaust valve opening ${ }^{6}$. For instance, Figure 3 shows that the amplitude of the exhaust gas pressure wave (pulse) from cylinder 1 drops do the sufficiently low level before the exhaust stroke starts in cylinder 2. In general, the use of a branched exhaust manifold enables to decrease the average pressure in individual branches, which leads to the decrease of engine pumping losses, fuel consumption, and smoking during engine acceleration.

The curves shown in Fig. 3 also reveal slight decrease of amplitudes of the exhaust gas pressure waves flowing from the cylinders situated in the central parts of the exhaust manifolds, close to the turbine, as compared to the outlets situated far from the turbine?

\footnotetext{
${ }^{5}$ During the scavenging stroke, in order to remove as much of the exhaust gas as possible, the pressure in the exhaust manifold is to be lower than the charge pressure.

${ }^{6}$ Equal usually to 240 degrees of OWK in four-stroke engines.

${ }^{7}$ All pressure waves (pulses) leave part of kinetic energy on the way between the exhaust valves and the turbine stator due to friction, flow resistance in elbow connections, etc.
} 


\begin{tabular}{|c|c|c|c|c|c|}
\hline Load & $0,25 \mathrm{Pe}$ & $0,50 \mathrm{Pe}$ & $0,75 \mathrm{Pe}$ & $1,0 \mathrm{Pe}$ & $1,1 \mathrm{Pe}$ \\
\hline \multicolumn{6}{|l|}{ Parameter } \\
\hline Rotational speed of crankshaft $-\mathrm{n}\left[\mathrm{min}^{-1}\right]$ & 750 & 750 & 750 & 750 & 750 \\
\hline Average effective pressure - pe [MPa] & 0,37 & 0,74 & 1,10 & 1,48 & 1,63 \\
\hline Effective power - Pe $[\mathrm{kW}]$ & 105 & 210 & 314 & 419 & 461 \\
\hline Engine load index: reg./siln. - Wo [-] & $3,9 / 3,8$ & $5,0 / 5,1$ & $6,2,6,2$ & $7,7 / 7,7$ & $8,3 / 8,3$ \\
\hline Fuel consumption per hour - Ge $[\mathrm{kg} / \mathrm{h}]$ & 26,4 & 46,8 & 68,6 & 90,1 & 100,8 \\
\hline Specific fuel consumption - ge [g/kWh] & 251,4 & 222,8 & 218,4 & 215,0 & 218,6 \\
\hline \multicolumn{6}{|l|}{ Cylinder pressure - maximal: } \\
\hline cylinder $1-\mathrm{p}_{\operatorname{maxC1}}[\mathrm{MPa}]$ & 6,4 & 8,4 & 9,7 & 11,2 & 12,1 \\
\hline cylinder $2-\mathrm{p}_{\operatorname{maxC2}}[\mathrm{MPa}]$ & 6,4 & 8,5 & 10,0 & 11,4 & 12,1 \\
\hline cylinder $3-\mathrm{p}_{\operatorname{maxC} 3}[\mathrm{MPa}]$ & 6,2 & 8,7 & 10,1 & 11,5 & 12,4 \\
\hline cylinder $4-\mathrm{p}_{\operatorname{maxC} 4}[\mathrm{MPa}]$ & 6,5 & 8,6 & 9,8 & 11,3 & 12,1 \\
\hline cylinder $5-\mathrm{p}_{\operatorname{maxC5}}[\mathrm{MPa}]$ & 6,2 & 8,4 & 9,7 & 11,5 & 12,4 \\
\hline cylinder $6-\mathrm{p}_{\max 6}[\mathrm{MPa}]$ & 6,4 & 8,5 & 9,7 & 11,2 & 12,2 \\
\hline \multicolumn{6}{|l|}{ Coolant: } \\
\hline Pressure $-\mathrm{p}_{\mathrm{CH}}[\mathrm{MPa}]$ & 0,24 & 0,24 & 0,24 & 0,24 & 0,24 \\
\hline Temp. in front of/behind air cooler $-\mathrm{t}_{\mathrm{CH} 1} / \mathrm{t}_{\mathrm{CH} 2}\left[{ }^{\circ} \mathrm{C}\right]$ & $22 / 23$ & $23 / 25$ & $24 / 27$ & $26 / 31$ & $27 / 34$ \\
\hline Temp. in front of engine $-\mathrm{t}_{\text {CHS1 }}\left[{ }^{\circ} \mathrm{C}\right]$ & 66 & 68 & 71 & 74 & 76 \\
\hline Temp. behind engine $-\mathrm{t}_{\mathrm{CHS} 2}\left[{ }^{\circ} \mathrm{C}\right]$ & 72 & 74 & 78 & 81 & 83 \\
\hline \multicolumn{6}{|l|}{ Lubricating oil: } \\
\hline Pressure $-\mathrm{p}_{\mathrm{ol}}[\mathrm{MPa}]$ & 0,38 & 0,38 & 0,38 & 0,38 & 0,38 \\
\hline Temp. in front of engine $-\mathrm{t}_{\text {oll }}\left[{ }^{\circ} \mathrm{C}\right]$ & 56 & 58 & 60 & 62 & 64 \\
\hline Temp. behind engine $-\mathrm{t}_{\mathrm{ol} 2}\left[{ }^{\circ} \mathrm{C}\right]$ & 66 & 68 & 70 & 72 & 74 \\
\hline \multicolumn{6}{|l|}{ Charge air: } \\
\hline Pressure $-\mathrm{p}_{\mathrm{d}}[\mathrm{MPa}]$ & 0,011 & 0,046 & 0,084 & 0,134 & 0,157 \\
\hline Temp. in front of/behind air cooler $-\mathrm{t}_{\mathrm{dCH} 1} / \mathrm{t}_{\mathrm{dCH} 2}\left[{ }^{0} \mathrm{C}\right]$ & $42 / 24$ & $72 / 28$ & $96 / 33$ & $130 / 43$ & $140 / 47$ \\
\hline \multicolumn{6}{|l|}{ Exhaust gas: } \\
\hline Temp. behind cylinder $1-\mathrm{t}_{\mathrm{C} 1}\left[{ }^{0} \mathrm{C}\right]$ & 255 & 285 & 315 & 365 & 365 \\
\hline Temp. behind cylinder $2-\mathrm{t}_{\mathrm{C} 2}\left[{ }^{\circ} \mathrm{C}\right]$ & 260 & 285 & 335 & 375 & 390 \\
\hline Temp. behind cylinder $3-\mathrm{t}_{\mathrm{C} 3}\left[{ }^{\circ} \mathrm{C}\right]$ & 235 & 280 & 310 & 340 & 355 \\
\hline Temp. behind cylinder $4-\mathrm{t}_{\mathrm{C} 4}\left[{ }^{\circ} \mathrm{C}\right]$ & 270 & 300 & 330 & 370 & 375 \\
\hline Temp. behind cylinder $5-\mathrm{t}_{\mathrm{C} 5}\left[{ }^{\circ} \mathrm{C}\right]$ & 270 & 295 & 315 & 350 & 365 \\
\hline Temp. behind cylinder $6-\mathrm{t}_{\mathrm{C} 6}\left[{ }^{0} \mathrm{C}\right]$ & 255 & 290 & 315 & 345 & 360 \\
\hline Aver. temp. behind cylinders $-\mathrm{t}_{\mathrm{CSr}}\left[{ }^{0} \mathrm{C}\right]$ & 258 & 289 & 320 & 358 & 368 \\
\hline Temp. in front of turbine (cylinders $1,2,3)-\mathrm{t}_{\mathrm{Tk} 1}\left[{ }^{\circ} \mathrm{C}\right]$ & 305 & 395 & 450 & 495 & 510 \\
\hline Temp. in front of turbine (cylinders $4,5,6)-\mathrm{t}_{\mathrm{Tk} 2}\left[{ }^{\circ} \mathrm{C}\right]$ & 320 & 390 & 440 & 485 & 505 \\
\hline Temp. behind turbine $-\mathrm{t}_{\mathrm{TT} 2}\left[{ }^{\circ} \mathrm{C}\right]$ & 265 & 325 & 350 & 360 & 380 \\
\hline $\begin{array}{l}\text { Total pressure loss in exhaust manifold (exhaust gas } \\
\text { outlet backpressure) }-p_{c k}[\mathrm{~Pa}]\end{array}$ & 400 & 800 & 1500 & 2500 & 2800 \\
\hline Fuel pressure in front of engine $-\mathrm{p}_{\mathrm{pal}}[\mathrm{MPa}]$ & 0,24 & 0,24 & 0,23 & 0,23 & 0,25 \\
\hline
\end{tabular}

8 To improve readability of the presented information, a decision was made to preserve, only in this case, the Celsius temperature scale in the collation of control engine parameters the values of which are read directly from standard measuring instruments. 
This phenomenon results from the nature of expansion of the exhaust gas from central cylinders. In this case the exhaust gas expands in two directions: towards the turbine and towards the beginning of the manifold. The amplitude reduction is larger for larger volumes of the side branches of the connecting channel [Korczewski and Zacharewicz, 2012].

\section{TECHNOLOGY OF EXHAUST GAS TEMPERATURE MEASUREMENT}

In the analysed marine engines with pulse turbocharging, the exhaust gas from cylinder heads flows with large speed (considerably above $50 \mathrm{~m} / \mathrm{s}$ ) ${ }^{9}$ to the turbocompressor, initially through thermally insulated elbow connectors, and then through the insulated manifold of constant cross-section ${ }^{10}$ Fig. 4. Thermal deformations of the channel are taken over by compensators made of materials revealing good resistance to high temperatures. These compensators are installed between particular channel segments - Fig. 5 .

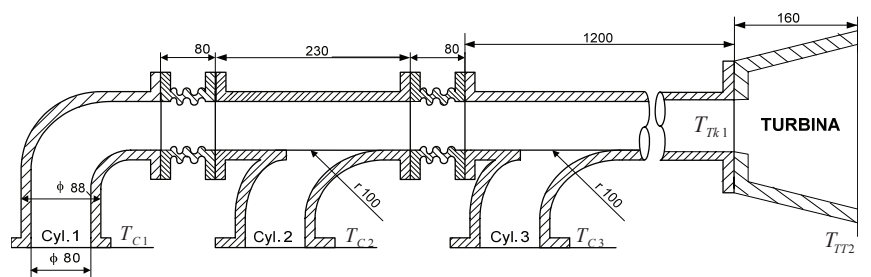

Fig. 4. Scheme of the exhaust manifold

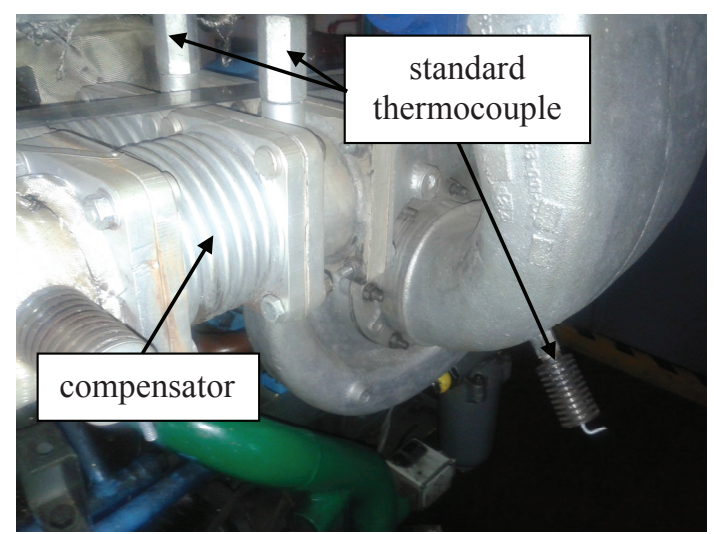

Fig. 5. General view of pulse supply channels for the turbocompressor

In stationary conditions of engine operation, this process can be treated as the periodically changing (stationary) and energetically isolated flow, i.e. the adiabatic flow with no technical work [Wiśniewski, 2005]. However, friction losses connected with the viscosity of the flowing exhaust gas are to be taken into account (irreversible adiabatic). In this situation,

9 During the scavenging stroke, after opening of the exhaust valve the longitudinal acoustic (pressure) wave is generated. This wave moves with the local speed of sound with respect to the flowing exhaust gas particles. 10 As was explained in the previous Chapter, at least two branches of this type are used in the pulse-type exhaust gas supply system of the six-cylinder engine turbocompressor. assuming that the volume of the exhaust gas flow per unit time does not change, the flux of the exhaust gas enthalpy through each cross-section of the channel connecting the cylinder with the turbocompressor also remains unchanged:

$$
\dot{H}^{*}=\dot{m} \cdot c_{p} \cdot T^{*}=i d e m
$$

What is subject to change (transformation) in this case, is the proportion of contributions of particular components of the exhaust gas enthalpy flux, representing the following types of energy ${ }^{11}$ - Fig. 6:

$$
\begin{aligned}
& \text { - kinetic energy } e_{k}=\frac{c^{2}}{2}, \\
& \text { - pressure (pumping) energy } e_{p}=\frac{p}{\rho} \text {, } \\
& \text { - internal energy } u=c_{v} \cdot T .
\end{aligned}
$$
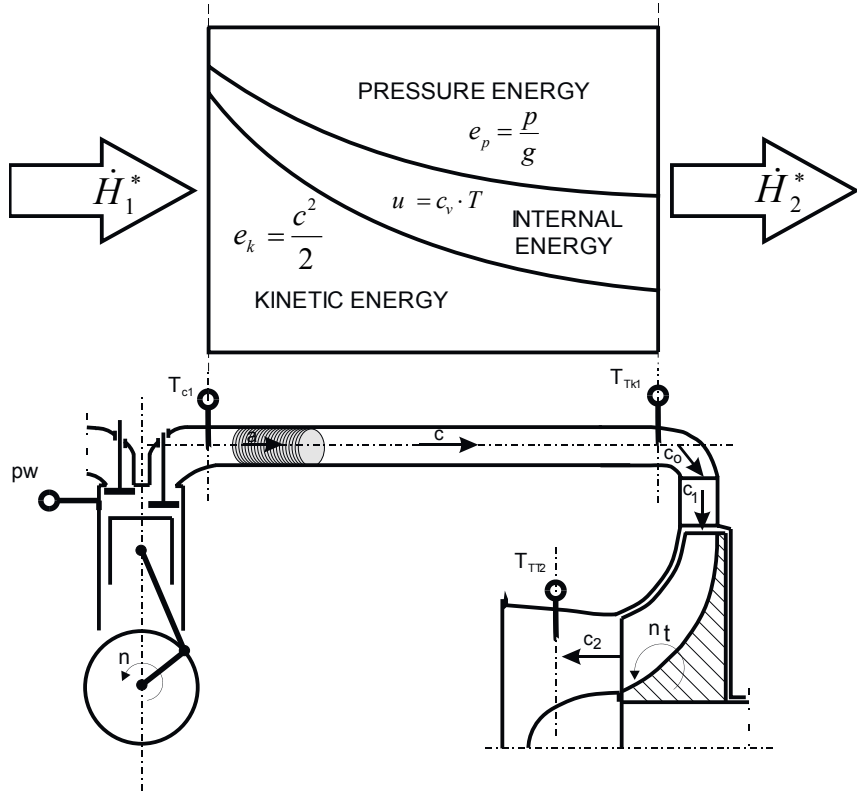

Fig. 6. Energy changes in the exhaust manifold

In the turbocompressor supply system, successive pulses of hot exhaust gas which leave the engine cylinders compress adiabatically the gas column situated in front of them [Woodyard, 2004]. The increasing hydraulic resistance slows down the flow and provokes dissipation of kinetic energy of the compressed fluid, accompanied by the increase of its internal energy (the fluid absorbs the generated friction heat) and the pressure energy (gas pumping work), the observable symptoms of which are the decrease of the exhaust gas flow velocity and the increase of its static temperature and pressure in the turbocompressor turbine cross-section. The temperature increase in front of the turbine can be very high, and exceed the exhaust gas temperature measured directly behind the

\footnotetext{
${ }^{11}$ Potential energy changes of the exhaust gas flow are negligibly small and can be omitted in the energy balance.
} 
cylinders by $100 \mathrm{~K}$ and more.

The above described phenomenon is not the only reason for the observed increase of the exhaust gas temperature in the turbocompressor supply channel. Other factors which remarkably affect the observed anomaly are the following:

In the exhaust manifold, made of heat resistant or stainless steel, the reaction of catalytic oxidation (final combustion) of non-burned hydrocarbon particles takes place on the inner surface of the flow channel in the presence of iron oxides (the catalytic effect of iron oxides, for instance $\mathrm{Fe} 2 \mathrm{O} 3$ ) which leads to the increase of the exhaust gas temperature in front of the turbine.

The thermocouple situated directly behind the exhaust valve records the averaged temperature of the exhaust gas flow pulse. This thermocouple is exposed to the action of very hot exhaust gas in the initial phase of its outflow, and then of a much colder mixture of exhaust gas and charge air during cylinder scavenging. This area is not reached by hot exhaust gas particles flowing out from other cylinders (but can be reached by the exhaust gas pressure waves of both primary and reflected type). At the same time the thermocouple situated in the exhaust manifold directly in front of the turbine is exposed to the action of successive exhaust gas flow pulses approaching the turbine with the frequency which generally depends on the number of cylinders connected to the manifold and in the present case is three times as high as that recorded by thermocouples installed in the connector pipes directly behind the cylinders. All this results in the increase of indications of the averaged exhaust gas temperature in front of the turbocompressor, as compared to those recorded behind the engine cylinders.

\section{DIAGNOSTIC INFERENCE}

The excessive increase of the exhaust gas temperature behind the cylinder is particularly dangerous for the reliability of cylinder valves, while exceeding its permissible value in the turbocompressor inlet cross-section can result in vast and usually irreversible damages of turbine stator and rotor blades. That is why this parameter is on-line monitored in the process of operation of modern marine engines.

A number of operating reasons for excessive increase of the exhaust gas temperature can be named. In marine engines it is usually connected with:

excessive engine load, resulting from hull fouling or damage of propeller screw blades (collisions, running aground, etc.);

disturbances in functioning of the water installation system which cools cylinder liners (flow ducts obstructed by hardly removable deposits of impurities, air-locked water spaces, etc.); pollution of the exhaust manifold: products of incomplete fuel combustion in cylinders form layers of deposits on the inner surfaces of the exhaust gas flow channel and on the surfaces of turbine stator and rotor blades, thus decreasing the active cross-sections of the exhaust gas flow channel and provoking all further consequences accompanying the exhaust gas temperature increase, such as the decreasing efficiency and reliability of the engine and turbocompressor [Piotrowski and Witkowski, 2002]); disturbances in functioning of the executive mechanism of the control system of adjustable turbocompressor stator blades (deformations, impurities, cracks, jamming, etc.);

disturbances of the fuel combustion process in cylinders due to:

incorrect functioning of the engine fuel supply system (low quality of fuel, faulty injection pump or injectors - Fig. 7),

dysfunction of the charge air system (jammed filter at compressor air inlet, polluted cooler, damaged compressor rotor blades or diffuser);

disturbances in functioning of the working medium valve train (worn out or polluted seats, faces, and/or heads of inlet and exhaust valves, worn out mechanical, hydraulic, or pneumatic valve drive elements).

Another cause of excessive, and usually rapid, increase of the exhaust gas temperature in case of two-stroke engines can be spontaneous combustion of oil mist in the charge air container, most frequently due to the backflow of the hot exhaust gas from cylinders to the container through the leaking piston rings [Scott, 2011]).

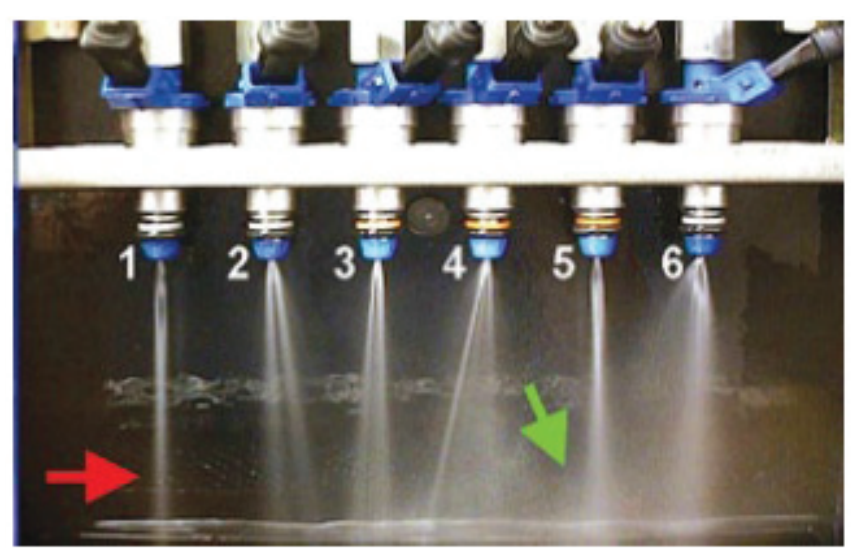

Fig. 7. Pattern of possible disturbances in injectors' operation - full set from the same engine [www.intercars.com.pl]

The exhaust gas temperature measured in characteristic control cross-sections of the flow channel is a basic control parameter of the engine. This parameter is online monitored during engine operation - Table 2. Systematic temperature measurements can make the basis for evaluating diagnostic parameters which will enable, in turn, to diagnose general technical condition of workspaces of functional systems of the engine, the ship hull, or even the ship propeller [Korczewski, 2012]:

- Exhaust temperature increase along the duct between the cylinder and the turbocompressor $-\Delta \mathrm{T}_{C i}$ :

$$
\Delta T_{C i}=T_{C i}-T_{T k i}
$$

where: $\mathrm{T}_{C i}$ is the exhaust gas temperature of the $\mathrm{i}$-th cylinder, and $\mathrm{T}_{T k i}$ is the exhaust gas temperature in the exhaust manifold in front of the turbine. 
- Dispersion of the exhaust gas temperature around the average value $-\delta T_{C i}$ :

$$
\delta T_{C i}=\frac{T_{C i}-T_{C s r}}{T_{C s r}} \cdot 100 \%
$$

where: $T_{C i}$ is the exhaust gas temperature of the $\mathrm{i}$-th cylinder, and $T_{C s r}$ is the averaged (arithmetic mean) temperature of the exhaust gas from engine cylinders.

- Unevenness of the exhaust gas temperature in the exhaust manifolds supplying the turbocompressor $-\delta T_{T k}$ :

$$
\delta T_{T k}=\frac{T_{T k 1}-T_{T k 2}}{T_{T k s r}} \cdot 100 \%
$$

where: $T_{T k 1}, T_{T k 2}$ are the exhaust gas temperatures in the exhaust manifolds in front of the turbine, and $T_{T k s r}$ is the averaged exhaust gas temperature in the exhaust manifolds in front of the turbine.

- Relative spread of the exhaust gas temperature $-\delta T_{C S}$ :

$$
\delta T_{S}=\frac{T_{C \max }-T_{C \min }}{T_{C S r}} \cdot 100 \%
$$

where: $T_{C \max }, T_{C \min }$ is, respectively, the maximal and minimal value of the exhaust gas temperature from cylinders, and $T_{C s r}$ is the averaged temperature of the exhaust gas from engine cylinders.

- Temperature ratio in turbine $-\varepsilon T_{T S}$ :

$$
\varepsilon T_{T S}=\frac{T_{T k s r}}{T_{T T 2}} \cdot 100 \%
$$

The numerical values collected in Table 2 can make the basis for creating a diagnostic matrix representing the influence of well-known and identified states of operating inability of workspaces and functional systems of the analysed engine type on the values of the above defined temperature based diagnostic parameters - Table 3. In this case, operating and diagnostic tolerances of these parameters are to be defined first [Korczewski, 2011]. This metrological task is extremely complex and requires expensive and hazardous experimental engine examination, including introduction of real changes to the parameters characterising the constructional structure of the engine12. Another option is or multiannual observation of operation of a large number of engines of the same type installed in the ship engine room without further interference into their technical condition. Completely new opportunities

\begin{tabular}{|c|c|c|c|c|c|}
\hline $\begin{array}{l}\text { Load } \\
\text { Parameter }\end{array}$ & $0,25 \mathrm{Pe}$ & $0,50 \mathrm{Pe}$ & 0,75 Pe & $1,0 \mathrm{Pe}$ & $1,1 \mathrm{Pe}$ \\
\hline \multicolumn{6}{|c|}{ Control parameter } \\
\hline $\mathrm{T}_{\mathrm{Cl}}[\mathrm{K}]$ & 528 & 558 & 588 & 638 & 638 \\
\hline $\mathrm{T}_{\mathrm{C} 2}[\mathrm{~K}]$ & 533 & 558 & 608 & 648 & 663 \\
\hline $\mathrm{T}_{\mathrm{C} 3}[\mathrm{~K}]$ & 508 & 553 & 583 & 613 & 628 \\
\hline $\mathrm{T}_{\mathrm{C} 4}[\mathrm{~K}]$ & 543 & 573 & 603 & 643 & 648 \\
\hline $\mathrm{T}_{\mathrm{C} 5}[\mathrm{~K}]$ & 543 & 568 & 588 & 623 & 638 \\
\hline $\mathrm{T}_{\mathrm{C} 6}[\mathrm{~K}]$ & 528 & 563 & 588 & 618 & 633 \\
\hline $\mathrm{T}_{\mathrm{Csr}}[\mathrm{K}]$ & 531 & 562 & 593 & 631 & 641 \\
\hline $\mathrm{T}_{\mathrm{Tk1}}[\mathrm{K}]$ & 578 & 668 & 723 & 768 & 783 \\
\hline $\mathrm{T}_{\mathrm{Tk} 2}[\mathrm{~K}]$ & 593 & 663 & 713 & 758 & 778 \\
\hline $\mathrm{T}_{\mathrm{TT2}}[\mathrm{K}]$ & 538 & 598 & 623 & 633 & 653 \\
\hline $\mathrm{T}_{\mathrm{Tksir}}[\mathrm{K}]$ & 585,5 & 665,5 & 718 & 763 & 780,5 \\
\hline \multicolumn{6}{|c|}{ Diagnostic parameter } \\
\hline$\Delta \mathrm{T}_{\mathrm{Cl}}[\mathrm{K}]$ & 50 & 110 & 135 & 130 & 145 \\
\hline$\Delta \mathrm{T}_{\mathrm{C} 2}[\mathrm{~K}]$ & 45 & 110 & 115 & 120 & 120 \\
\hline$\Delta \mathrm{T}_{\mathrm{C} 3}[\mathrm{~K}]$ & 70 & 115 & 140 & 155 & 155 \\
\hline$\Delta \mathrm{T}_{\mathrm{C}_{4}}[\mathrm{~K}]$ & 50 & 90 & 110 & 115 & 130 \\
\hline$\Delta \mathrm{T}_{\mathrm{C} 5}[\mathrm{~K}]$ & 50 & 95 & 125 & 135 & 140 \\
\hline$\Delta \mathrm{T}_{\mathrm{C}_{6}}[\mathrm{~K}]$ & 65 & 100 & 125 & 140 & 145 \\
\hline$\delta \mathrm{T}_{\mathrm{Cl}}[\%]$ & $-0,56$ & $-0,71$ & $-0,84$ & 1,11 & $-0,47$ \\
\hline$\delta \mathrm{T}_{\mathrm{C} 2}[\%]$ & 0,38 & $-0,71$ & 2,53 & 2,69 & 3,43 \\
\hline$\delta \mathrm{T}_{\mathrm{C} 3}[\%]$ & $-4,33$ & $-1,60$ & $-1,69$ & $-2,85$ & $-2,03$ \\
\hline$\delta \mathrm{T}_{\mathrm{C} 4}[\%]$ & 2,26 & 1,96 & 1,69 & 1,90 & 1,09 \\
\hline$\delta \mathrm{T}_{\mathrm{C} 5}[\%]$ & 2,26 & 1,07 & $-0,84$ & $-1,27$ & $-0,47$ \\
\hline$\delta \mathrm{T}_{\mathrm{C} 6}[\%]$ & $-0,56$ & 0,18 & $-0,84$ & $-2,06$ & $-1,25$ \\
\hline$\delta \mathrm{T}_{\mathrm{s}}[\%]$ & 6,59 & 3,56 & 3,37 & 4,75 & 3,12 \\
\hline$\delta \mathrm{T}_{\mathrm{Tk}}[\%]$ & $-2,56$ & 0,75 & 1,39 & 1,31 & 0,64 \\
\hline$\varepsilon \mathrm{T}_{\mathrm{TS}}[\%]$ & 1,09 & 1,11 & 1,15 & 1,21 & 1,20 \\
\hline
\end{tabular}
in this area have been brought by numerical methods and
Table 2. Values of exhaust gas temperature treated as control and diagnostic parameter

computer codes used to simulate engine operation processes and various types of defects [Korczewski, 2010]. However in each analysed case, the obtained results of simulation analyses require final experimental verification on a real object.

Table 3. Hypothetical diagnostic matrix for engine with pulse turbocharging system. "1", „0"- diagnostic parameter which, respectively, reacts or not to the inability state Sni by exceeding the boundaries of the diagnostic tolerance area.

\begin{tabular}{|c|c|c|c|c|c|c|c|}
\hline $\begin{array}{c}\text { Inability state } \\
\text { Diagnostic parameter }\end{array}$ & $S n 1$ & $S n 2$ & $S n 3$ & $S n 4$ & $S n 5$ & $S n 6$ & $S n i$ \\
\hline$\Delta T_{\mathrm{Ci}}$ & $1 / 0$ & $1 / 0$ & $1 / 0$ & $1 / 0$ & $1 / 0$ & $1 / 0$ & $1 / 0$ \\
\hline$\delta T_{\mathrm{Ci}}$ & $1 / 0$ & $1 / 0$ & $1 / 0$ & $1 / 0$ & $1 / 0$ & $1 / 0$ & $1 / 0$ \\
\hline$\delta \mathrm{T}_{\mathrm{S}}$ & $1 / 0$ & $1 / 0$ & $1 / 0$ & $1 / 0$ & $1 / 0$ & $1 / 0$ & $1 / 0$ \\
\hline$\delta \mathrm{T}_{\mathrm{TK}}$ & $1 / 0$ & $1 / 0$ & $1 / 0$ & $1 / 0$ & $1 / 0$ & $1 / 0$ & $1 / 0$ \\
\hline$\varepsilon \mathrm{T}_{\mathrm{TS}}$ & $1 / 0$ & $1 / 0$ & $1 / 0$ & $1 / 0$ & $1 / 0$ & $1 / 0$ & $1 / 0$ \\
\hline
\end{tabular}

${ }^{12}$ Analysed only in laboratory conditions. 


\section{FINAL REMARKS AND CONCLUSIONS}

The article presents opportunities for making general evaluation of technical condition of a marine ship with pulse turbocharging system based on standard exhaust gas temperature measurements performed in characteristic control cross-sections of the thermal and flow systems of the engine, in stationary conditions of ship motor system operation. This evaluation makes the basis for further more detailed diagnostic analyses, provided that the time-histories of functions describing high-speed thermal and flow processes in the exhaust manifold are aperiodic within the time duration of one cycle of engine operation. This approach requires working out a new technology of on-line measurements of instantaneous values of the exhaust gas temperature in the channel connecting the cylinders with the turbocompressor, in order to determine precisely the nature of enthalpy flux changes of the exhaust gas supplying the turbocompressor.

\section{BIBLIOGRAPHY}

1. Korczewski Z.: An entropy function application within the selection process of diagnostic parameters of marine diesel and gas turbine engines. Polish Maritime Research, 2(65)/2010, Vol.17, p. 29-35.

2. Korczewski Z.: Exhaust gas temperature measurements in diagnostic examination of naval gas turbine engines. Part III. Diagnostic and operating tolerances. Polish Maritime Research, No. 4(71)/2011, Vol.18, p. 49-53.

3. Korczewski Z.: Analysing possible use of the diagnostic model of internal combustion engine piston-crankshaft systems and evaluating its practical applicability to rational control of the process of their operation taking into account the expert system (in Polish). Work within the framework of the Research Project No. N509 494638 financed by MNiSW. Gdansk University of Technology, 2012.

4. Korczewski Z., Zacharewicz M.: Alternative diagnostic method applied on marine diesel engines having limited monitoring susceptibility. Transactions of the Institute of Measurement and Control, Great Britain SAGE - Vol. 34, No. 8/December/2012, 2012, p. 937-946.

5. Kluj S.: Diagnostics of marine equipment (in Polish). Monographic publication. AM Gdynia 2000.

6. Pfriem, H.: Zur messung vernderlicher temperaturen von gasen und flssigkeiten (On the measurement of fluctuating temperatures of gases and fluids). Forschung auf dem Gebiete des Ingenieurwesens,7(2)/1936, pp. 8592 (in German).

7. Piotrowski I., Witkowski K.: Operation of marine internal combustion engines (in Polish). Monographic publication.
Gdynia Maritime Academy, Gdynia 2002.

8. Rychter T., Teodorczyk A.: Theory of piston engines (in Polish). WKiŁ, Warszawa 2006.

9. Scott W.: Diagnosing Causes of High EGT in Marine Engines. Marine Machinery, Engines \& Controls. Edited by Lamar Stonecypher (updated: 11/2/2011).

10. Wisłocki K.: Turbocharging systems for high-speed internal combustion engines (in Polish) WKie, Warsaw 1991.

11. Wiśniewski S.: Technical thermodynamics (in Polish). WNT, Warsaw 2005.

12. Wiśniewski S.: Temperature measurements in tests of engines and thermal facilities (in Polish). WNT, Warsaw 1983.

13. Woodyard D.: Pounders marine diesel engines and gas turbine. Great Britain ELSEVIER, 2004 (eighth edition).

14. Wojnowski W.: Marine internal combustion engine power plants (in Polish). Part I. Polish Naval Academy. Gdynia 1998.

15. www.intercars.com.pl

\section{CONTACT WITH THE AUTHOR}

Zbigniew Korczewski

Gdańsk University of Technology

11/12 Narutowicza St. 80 - 233 Gdańsk

Poland 